If the association between a disease and the HLA system is strong only relatively small numbers of patients and controls are necessary to confirm it, but when the association is weak, problems of sampling and statistical errors assume greater importance. These have been reviewed, ${ }^{7}$ and so far none of the reported associations between HLA antigens and asbestosis have achieved significance when the probability value has been multiplied by the total number of antigens tested. Ignoring the trend may, however, obscure the association, and further data should be obtained.

HLA-B12 was found in 18 of our $37\left(49_{\circ}^{\circ}\right)$ patients with asbestosis. This antigen was also found in 16 out of $20\left(80^{\circ}{ }_{0}\right)$ patients with cryptogenic fibrosing alveolitis ${ }^{\star}$ - a disorder similar to asbestosis but without the history of occupational exposure -and in four out of eight children with the highly pathogenic strain of Haemophilus influenza serotype B. ${ }^{9}$

If HLA-B12 does increase susceptibility to the damaging effects of asbestos on the lung and to the development of cryptogenic fibrosing alveolitis, this would imply that in the HLA region of chromosome 6 in man a pulmonary fibrogenic gene is in linkage disequilibrium with HLA-B12. Since the external agent in asbestosis is known it may prove possible to elucidate further the pathogenesis of asbestosis and the significance of the interaction of the HLA antigens with environmental precipitating factors in general.

The high prevalence of HLA-BW5 (tables II-V) in exposed workers without asbestosis and with clear radiographs raises the possibility that possession of this antigen may protect against the development of pulmonary fibrosis. This is not an entirely new concept since it has been shown that progressive massive fibrosis (PMF) occurs in a low percentage of coalminers ${ }^{10}$ with HLA-BW18. Moreover, patients with carcinoma of the bronchus survive longer after pneumonectomy ${ }^{11}$ if they are positive for HLA-BW19 and B5.

When exploring HLA associations with disease, studies of families offer confirmation of the findings, ${ }^{12}$ but it is unlikely that this will be possible in asbestos workers, who, unlike coalminers and cotton workers, do not traditionally follow relatives into similar work.

If further studies of HLA antigens are made in this disorder we cannot emphasise too strongly the need for applying rigid criteria for the diagnosis. ${ }^{13}$ Only in this way will meaningful results be obtained and those with an increased risk be recognised.

We thank Mrs A Knott for meticulous care in matching the controls and performing the pulmonary function tests and $\mathrm{Dr} M$ Perkin for collecting many of the samples. We also thank Mr C West, who gave valuable statistical advice.

\section{References}

${ }^{1}$ Merchant, J A, et al, British Medical fournal, 1975, 1, 189.

${ }^{2}$ Matej, H, and Lange, A, First International Symposium on $H L A$ and Disease, p 256. Paris, INSERM, 1976.

${ }^{3}$ International Classification of Radiographs of Pneumoconiosis, ILO-UC Classification, 1971. Geneva, International Labour Office, 1972.

${ }^{4}$ Soutar, C A, Turner-Warwick, M, and Parkes, W R, British Medical fournal, 1974, 3, 145.

5 Turner-Warwick, M, and Parkes, W R, British Medical fournal, 1970, 3, 492.

'Svejgaard, A, et al, Transplantation Reviews, 1975, 22, 3.

7 Svejgaard, A, et al, Tissue Antigens, 1974, 4, 95.

${ }^{8}$ Evans, C C, Thorax, 1976, 31, 483.

9 Tejani, A, et al, First International Symposium on HLA and Disease. p 264. Paris, INSERM, 1976.

${ }^{10}$ Major, P C, et al, American Review of Respiratory Diseases, 1975, 3, 917.

11 Rogantine, G M, and Dellon, P B, fournal of the National Cancer Institute, $1975,54,1283$.

12 Cudworth, A G, and Woodrow, J C, British Medical fournal, 1975, 3, 133.

13 Parkes, W R, Occupational Lung Disorders: London, Butterworths, 1974

(Accepted 6 Fanuary 1977)

\title{
Quinine-induced agranulocytosis: toxic effect of quinine bisulphate on bone marrow cultures in vitro
}

\author{
RUTH SUTHERLAND， P C VINCENT， E RAIK， K BURGESS
}

\section{Introduction}

Drug-induced agranulocytosis is a rare but potentially serious clinical problem, and in most cases the clinician can attempt to identify the causative agent only from the history and response to withdrawal. This is relatively simple with single-drug exposure but much more difficult, if not impossible, when several drugs have been used. Methods for identifying the causative agent in vitro are clearly desirable. We described a case of amodiaquine-induced agranulocytosis in which amodiaquine suppressed the in-vitro growth of marrow cells from the patient but not from a normal control. ${ }^{1}$ Since then a few other reports have appeared in which drugs known to have caused agranulocytosis have been tested against cultures of normal marrow cells but not against cells from patients with a suspected adverse reaction to the drug. ${ }^{2-4}$ Quinine is a documented but rare cause of agranulocytosis. ${ }^{5}$ We report a case in which it was proved in vitro to be the responsible agent.

\section{Clinical history}

A 64-year-old man with a five-year history of peripheral neuropathy and leg cramps was admitted to hospital for investigation. He had 
gross motor-sensory peripheral neuropathy, which was confirmed by nerve conduction studies, but extensive investigations failed to disclose a cause.

On admission oral quinine sulphate $300 \mathrm{mg}$ at night was given for the leg cramps. Three days later a routine blood count showed profound neutropenia. Quinine was stopped but dextropropoxyphene with paracetamol (Di-Gesic, Dista), as needed for analgesia, and nitrazepam, which had been started on admission, were continued. The neutrophil count rapidly recovered (fig 1) and no other adverse haematological effects were noted. Bone marrow aspirations were performed six and 21 days after stopping quinine. The aspirates were morphologically normal and were used for culture studies.

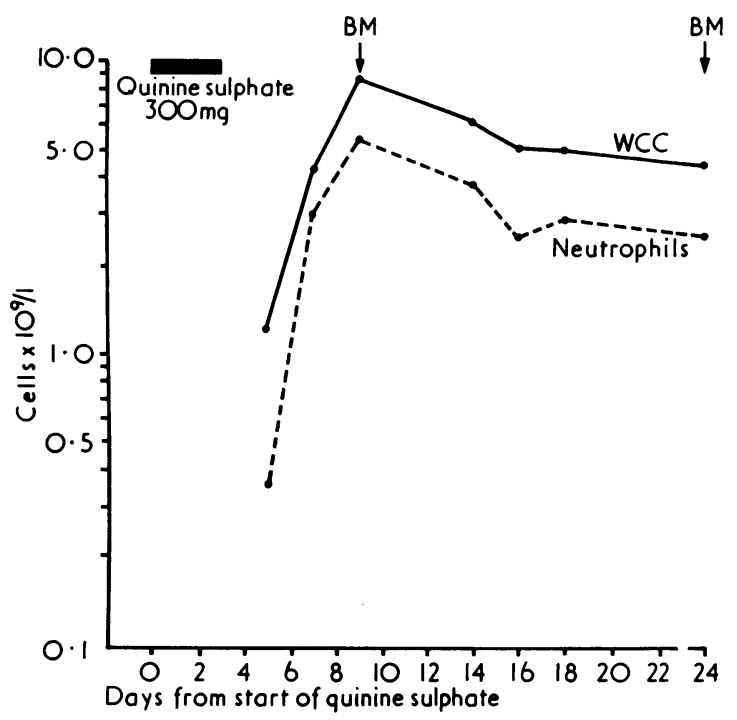

FIG 1-Changes in total white cell count (WCC) and neutrophil count after withdrawal of quinine. $\mathrm{BM}=$ Bone marrow aspiration.

\section{Method}

Bone marrow aspirates from the patient on days 9 and 24 (six and 21 days respectively after stopping quinine) were cultured in triplicate in semi-solid agar on feeder layers of peripheral blood leucocytes from two normal subjects by using the technique of Robinson and Pike. ${ }^{6}$ Marrow samples from haematologically normal patients who were undergoing anaesthesia for minor conditions and had given informed consent were cultured on feeder layers from the same source and used as controls. Quinine bisulphate was tested against cultures from the patient on both occasions, its stereoisomer quinidine (also as the bisulphate) being tested as well on the second occasion; they were added to the overlayer of bone marrow cells in concentrations equivalent to their estimated therapeutic plasma levels as well as at concentrations one-tenth and ten times as great. Concentrations of $1.82 \mu \mathrm{g} / \mathrm{ml}$ for quinine bisulphate and $5.0 \mu \mathrm{g} / \mathrm{ml}$ for quinidine bisulphate were selected as being equivalent to therapeutic plasma levels. ${ }^{7}$ Quinine bisulphate was tested in preference to quinine sulphate because of its greater solubility.

Cultures were scored after seven days' incubation by counting the number of colonies containing more than 50 cells. Results were expressed as a percentage of colony growth by the same marrow on the same feeder layers in the absence of drugs. Individual colonies were removed from control and test cultures and smears prepared for morphological examination.

\section{Results}

Both bone marrow samples from the patient grew normally in the absence of added drugs. The mean colony counts ( \pm SE of mean) obtained from these cultures were $79 \pm 5$ and $56 \pm 4$ respectively per $2 \times 10^{5}$ cells compared with the normal value in our laboratory of $50 \pm 5$ per $2 \times 10^{5}$ cells.

Significant inhibition of colony formation was observed when quinine was added to marrow cultures from the patient at the estimated plasma concentration of $1.82 \mu \mathrm{g} / \mathrm{ml}(\mathrm{P}<0.001$ for days 9 and 24) and at one-tenth that concentration $(P<0.001$ for day $9 ; 0.02>P$ 0.01 for day 24 ), whereas the controls showed no inhibition at these levels (fig 2). Quinine bisulphate at ten times the estimated plasma concentration inhibited colony formation in cultures from both the patient and the normal controls. By contrast, no inhibition of colony formation was observed when quinidine bisulphate was added to either the patient's cultures or the normal controls (fig 3).

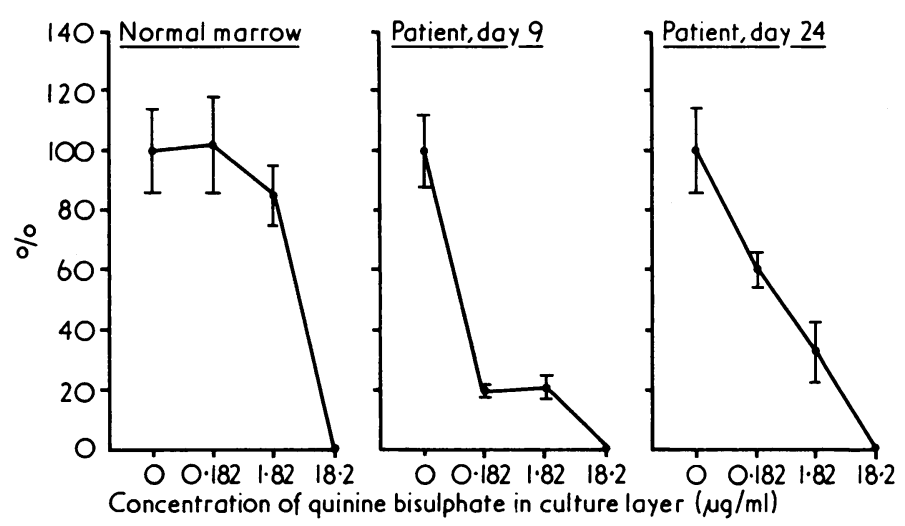

FIG 2-Culture results with marrow obtained from patient nine and 24 days after starting quinine (six and 21 days after stopping drug) and from two normal controls (results pooled) in presence of increasing concentrations of quinine bisulphate (equivalent therapeutic plasma concentration $1.82 \mu \mathrm{g} / \mathrm{ml}$ ). Results expressed as percentage of colony growth from untreated marrow. Bars indicate range mean \pm 2 SE of mean.

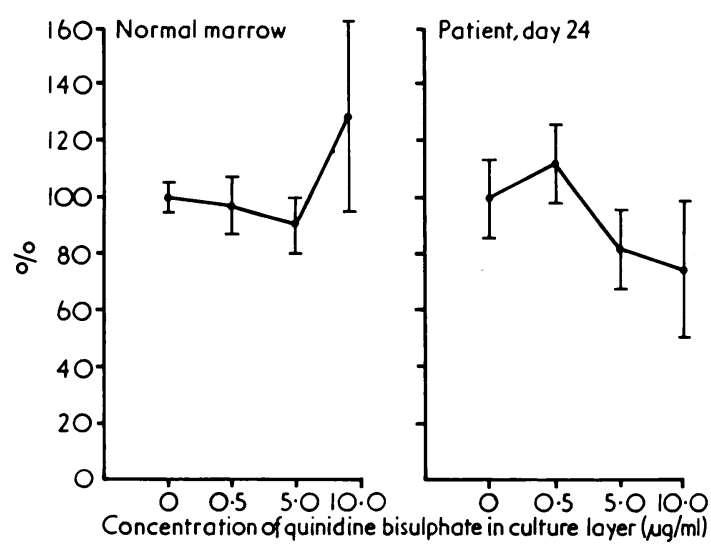

FIG 3-Culture results with marrow obtained from patient 24 days after starting quinine ( 21 days after stopping drug) and from two normal controls (results pooled) in presence of increasing concentrations of quinidine bisulphate (equivalent therapeutic plasma concentration $5.0 \mu \mathrm{g} / \mathrm{ml}$ ). Results expressed as percentage of colony growth from untreated marrow. Bars indicate range mean $\pm 2 \mathrm{SE}$ of mean.

\section{Discussion}

The in-vitro findings in this case support the clinical suspicion that quinine was responsible for the agranulocytosis and that the reaction was idiosyncratic, since pronounced toxic effects occurred with concentrations that had no effect on normal marrow. The failure to find any inhibition with quinidine, the D-rotatory stereoisomer of quinine, was particularly interesting and pointed to a high specificity in the toxic mechanism. Since most episodes of drug-induced agranulocytosis result from idiosyncrasy, it is hardly surprising that toxicity at concentrations equivalent to therapeutic plasma levels or less was seen only with cells from the patient. In such cases, testing drugs against normal marrow cultures alone is not likely to yield much useful information. 
Most workers agree that the cell that gives rise to colonies in the agar colony system is equivalent to the granulopoietic stem cell. " The formation of colonies, however, requires the activation of this cell and the serial proliferation of its progeny, and we cannot distinguish from our data whether quinine had a toxic effect on either or both of these mechanisms.

Our results encourage the further use of the marrow culture system for trying to identify in vitro drugs responsible for agranulocytosis in particular patients. At present only watersoluble drugs can be tested, which will remain a problem until non-toxic solvents for insoluble drugs are developed. A further obvious but none the less important precaution is not to test parenteral preparations containing preservatives, which are well known to be inhibitory in the marrow culture system.

\section{References}

${ }^{1}$ Lind, D E, Levi, I A, and Vincent, P C, British Medical fournal, 1973, 1, 458

${ }^{2}$ Howell, A, Andrews, T M, and Watts, R W E, Quarterly fournal of Medicine, 1973, 42, 834.

${ }^{3}$ Howell, A, et al, Clinical Science and Molecular Medicine, 1974, 46, 619.

4 Ratzan, R J, Moore, M A S, and Yunis, A A, Blood, 1974, 43, 363.

5 Hartl, P W, in Blood Disorders Due to Drugs and Other Agents, ed Ronald H Girdwood, p 147. Amsterdam, Excerpta Medica, 1973.

'Robinson, W A, and Pike, B L, in Hemopoietic Cellular Proliferation, ed F Stohlman jun, p 249, New York, Grune and Stratton, 1970.

Martindale: The Extra Pharmacopoeia, 26th ed, pp 439 and 1567. London, Pharmaceutical Press, 1972.

${ }^{8}$ Rickard, K A, et al, in Hemopoietic Cellular Proliferation, ed F Stohlman jun, p 238. New York, Grune and Stratton, 1970.

(Accepted 31 December 1976)

\title{
Metronidazole in prevention and treatment of bacteroides infections in elective colonic surgery
}

\author{
A T WILLIS, I R FERGUSON, P H JONES, K D PHILLIPS, P V TEARLE, R V FIDDIAN, \\ D F GRAHAM, D H C HARLAND, D F R HUGHES, D KNIGHT, W M MEE, N PASHBY, \\ R L ROTHWELL-JACKSON, A K SACHDEVA, IRENE SUTCH, CAROL KILBEY, \\ DEBORAH EDWARDS
}

British Medical fournal, 1977, 1, 607-610

\section{Summary}

A double-blind randomised trial was carried out among 46 patients undergoing elective colonic surgery; 27 patients received prophylactic metronidazole and 19 received placebo. Anaerobic infections did not develop in any of the metronidazole-treated patients, but did develop in $11(58 \%)$ of 19 controls who were subsequently successfully treated with metronidazole.

\section{Introduction}

Gastrointestinal surgery is associated with a high incidence of postoperative sepsis due to contamination of the field of operation by organisms from the intestine. An incidence of serious sepsis in excess of $50^{\circ}{ }^{\circ}$ is common. ${ }^{1-4}$

Luton and Dunstable Hospital, Luton LU4 0DZ

A T WILLIS, MD, FRACP, consultant microbiologist

I R FERGUSON, MB, DIPBACT, assistant bacteriologist

P H JONES, MB, MSC, trainee bacteriologist

K D PHILLIPS, BSC, senior scientific officer

P V TEARI.E, FIMLS, technician

R V FIDDIAN, FRCS, $\mathrm{MCH}$, consultant surgeon

D F GRAHAM, FRCS, surgical registrar

D H C HARLAND, FRCS, consultant surgeon

D F R HUGHES, FRCS, surgical registrar

D KNIGHT, FRACS, surgical registrar

W M MEE, FRCS, consultant surgeon

N PASHBY, MB, surgical registrar

R L ROTHWELL-JACKSON, FRCS, MCH, consultant surgeon

A K SACHDEVA, FRCS(ED), surgical registrar

IRENE SUTCH, MPS, district pharmaceutical officer

CAROL KILBEY, BPHARM, MPS, staff pharmacist

DEBORAH EDWARDS, BPHARM, MPS, staff pharmacist
Although the value of preoperative mechanical emptying of the bowel is not disputed, the use of prophylactic antibiotics in the preparation of patients for elective bowel surgery has remained controversial. ${ }^{5-10}$ Most studies of antibiotic prophylaxis have been concerned with control of infections due to aerobic bacteria, against which even prolonged courses of systemic antibiotics have frequently proved ineffective. Clearly the rational use of prophylactic antibiotics in colonic surgery requires an understanding of the bacterial flora encountered during surgery and of the sensitivity of the bacteria to various antibiotics.

There has been an increasing awareness of the importance of non-sporing anaerobes as a major cause of sepsis after surgery of the gastrointestinal tract. ${ }^{71-13}$ Indeed, recent studies ${ }^{13-15}$ which made use of the specific bactericidal activity of metronidazole against anaerobes in the prevention of postoperative sepsis after gastrointestinal and gynaecological surgery, strongly supported the view that aerobic bacteria are usually of only secondary importance in these clinical settings.

We report here the clinical and bacteriological findings of a double-blind trial of the value of metronidazole in the prophylaxis and treatment of sepsis after colonic surgery.

\section{Patients and methods}

All patients admitted to the Luton and Dunstable Hospital for elective colonic surgery during a 9-month period were admitted to the trial, provided that there was no recent history of antibiotic or metronidazole treatment. The study was a double-blind trial using active and placebo suppositories and oral tablets. Patients were randomly allocated to metronidazole and placebo groups.

Initially 64 patients were admitted to the study; 35 received prophylactic metronidazole and 29 were controls. During the study period 18 patients ceased to qualify for the trial-no colonic surgery was undertaken in seven, other antibiotic treatment was begun in eight, and the double-blind prophylaxis was incomplete in three patients. We therefore analysed 46 patients, 27 of whom received metronidazole (table I). Most operations were for malignant disease 